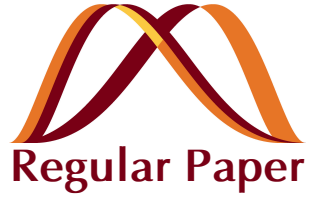

\section{Thermite Reaction Between CuO Nanowires and Al for the Crystallization of a-Si}

\author{
Do Kyung Kim \\ School of Electrical and Electronic Engineering, Yonsei University, Seoul 120-749, Korea and System LSI Samsung Electronics \\ Co. Ltd, Yongin 449-711, Korea
}

Jung Hyeon Bae and Hyun Jae $\mathrm{Kim}^{\dagger}$

School of Electrical and Electronic Engineering, Yonsei University, Seoul 120-749, Korea

Myung Koo Kang

Samsung Mobile Display, Cheonan 330-300, Korea

Received August 9, 2010; Accepted September 17, 2010

\begin{abstract}
Nanoenergetic materials were synthesized and the thermite reaction between the $\mathrm{CuO}$ nanowires and the deposited nano-Al by Joule heating was studied. $\mathrm{CuO}$ nanowires were grown by thermal annealing on a glass substrate. To produce nanoenergetic materials, nano- $\mathrm{Al}$ was deposited on the top surface of $\mathrm{CuO}$ nanowires. The temperature of the first exothermic reaction peak occurred at approximately $600^{\circ} \mathrm{C}$. The released heat energy calculated from the first exothermic reaction peak in differential scanning calorimetry, was approximately $1,178 \mathrm{~J} / \mathrm{g}$. The combustion of the nanoenergetic materials resulted in a bright flash of light with an adiabatic frame temperature potentially greater than $2,000^{\circ} \mathrm{C}$. This thermite reaction might be utilized to achieve a highly reliable selective area crystallization of amorphous silicon films.
\end{abstract}

Keywords: Thermite reaction, CuO nanowire, Selective area crystallization, RF sputtering

\section{INTRODUCTION}

Energetic materials are a class of materials having high amounts of stored chemical energy that is able to be rapidly released in the form of thermal energy. Energetic materials are generally composed of an oxidizer and a fuel which are physically mixed together. Energetic materials are used in explosives, pyrotechnics, and propellants; their properties make it possible to produce a greater amount of energy as compared to the input energy. Many technologies used for synthesizing nanoenergetic materials have been proposed. One of the simplest methods is a nanopowder mixed with fuel metal and oxidizer particles [1]. In addition, nanoenergetic materials can also be prepared by solgel [2], nanostructured multilayer foils [3,4], and nanocrystalline

\footnotetext{
${ }^{\dagger}$ Author to whom all correspondence should be addressed: E-mail: hjk3@yonsei.ac.kr
}

porous silicon with oxide [5]; these methods have difficulty in obtaining a homogeneous mixture, as well as hazardous and elaborate procedures. In this study, $\mathrm{Al} / \mathrm{CuO}$-based nanoenergetic materials were produced by integrating $\mathrm{CuO}$ nanowires grown from $\mathrm{Cu}$ thin film with nano-Al deposited onto a glass substrate. The fabricated nanoenergetic materials were characterized by scanning electron microscopy (SEM), X-ray diffraction (XRD), and differential scanning calorimetry (DSC). We investigated the heat flows and heat energies released from the $\mathrm{CuO}$ nanowires with deposited nano-Al; the results suggest that these could potentially be used for a-Si crystallization [6].

\section{EXPERIMENTS}

The nanoenergetic material sample was prepared as shown 

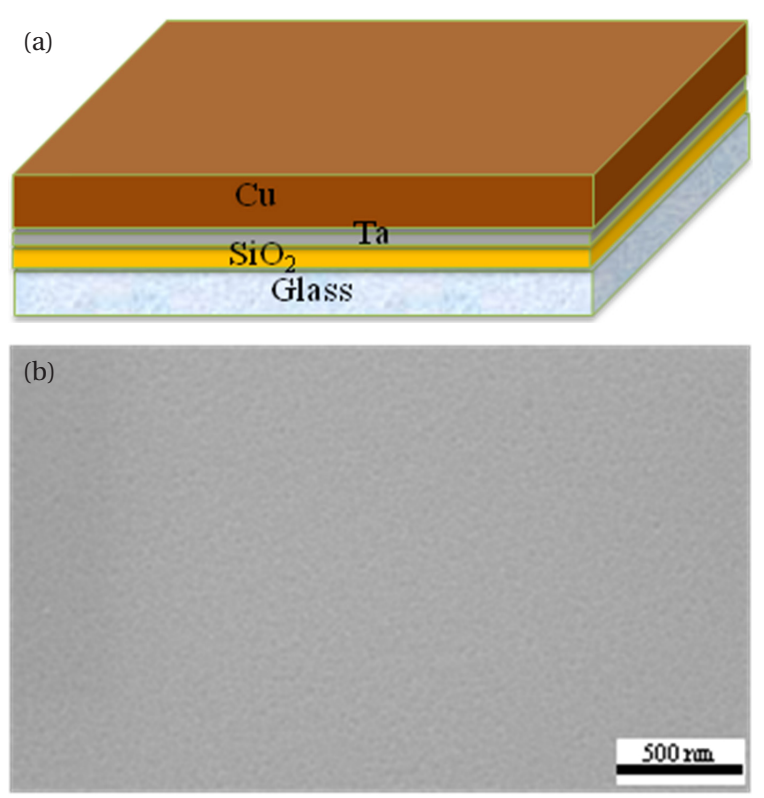

Fig. 1. Schematic diagram of nanoenergetic materials: (a) deposited Cu film, and (b) SEM images of the deposited 1-um-thick Cu film.

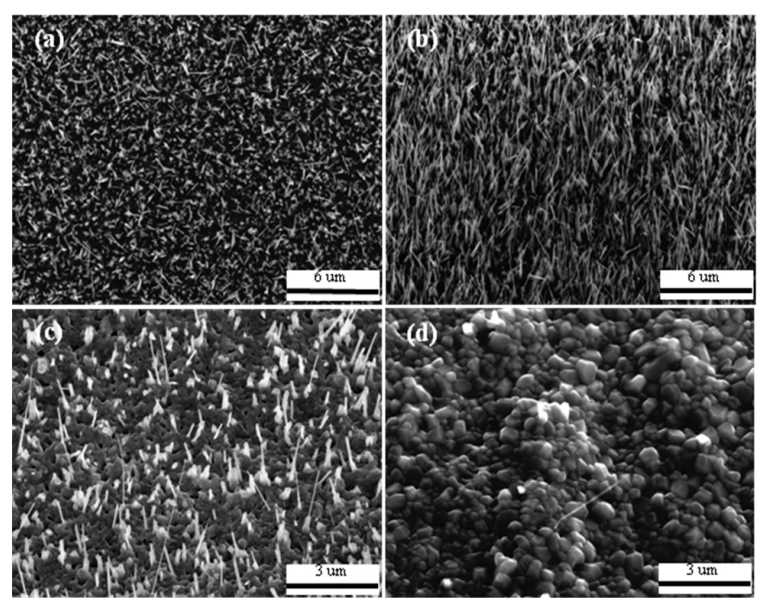

Fig. $2.30^{\circ}$-tilted view SEM images of $\mathrm{Cu}$ films annealed in static air for four h at (a) $400^{\circ} \mathrm{C}$, (b) $500^{\circ} \mathrm{C}$, (c) $600^{\circ} \mathrm{C}$, and (d) $700^{\circ} \mathrm{C}$.

in Fig. 1. Figure 1(a) shows the deposited $\mathrm{Cu}$ film as well as the other layers. 1-um-thick $\mathrm{Cu}$ thin film was deposited onto a glass substrate by RF sputtering. A 100 -nm-thick $\mathrm{SiO}_{2}$ film as a buffer layer and a 50-nm-thick Ta film as an adhesion layer were also deposited onto the glass substrate by RF sputtering. Figure 1(b) shows the top-view SEM image of the deposited $\mathrm{Cu}$ layer without the nano-wire structure. The native oxides of the $\mathrm{Cu}$ thin films were removed by a solution of $10 \mathrm{ml} \mathrm{HCl}$ and $60 \mathrm{ml}$ de-ionized water. The samples were placed in a quartz tube in the middle of a horizontal tube furnace; static air was used for annealing. The samples were annealed in a horizontal tube furnace at various temperatures for four hours, in order to determine the optimum annealing temperature. The annealed samples were allowed to naturally cool to prevent peel-off due to thermal stress. $\mathrm{CuO}$ nanowires grew from the 1- $\mu \mathrm{m}$-thick $\mathrm{Cu}$ thin film [7]. Nanoenergetic materials were produced by depositing a 1- $\mu$ m-thick $\mathrm{Al}$ on top by $\mathrm{RF}$ sputtering. The $\mathrm{CuO} / \mathrm{Al}$-based nanoenergetic materials on the glass substrate were characterized by SEM and XRD. The thermite reaction of $\mathrm{CuO}$ nanowires with the deposited nano-

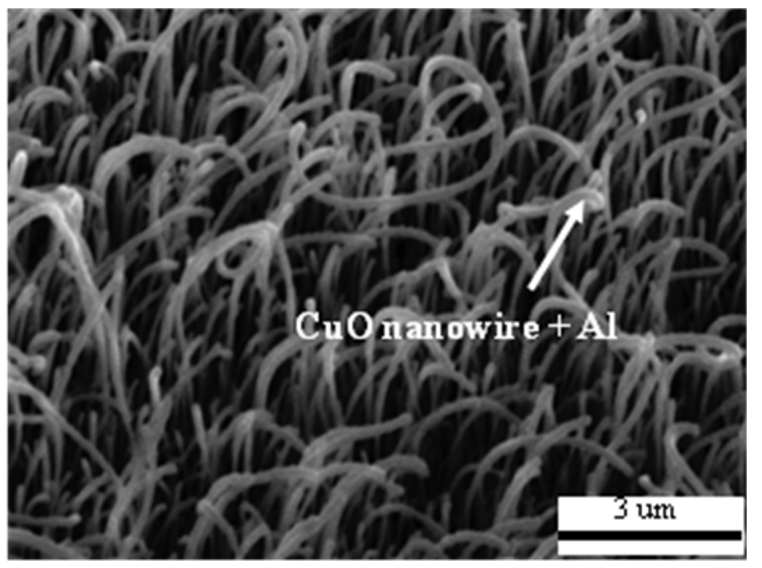

Fig. $3.30^{\circ}$-tilted view SEM images of $\mathrm{CuO}$ nanowires coated with deposited nano-Al.

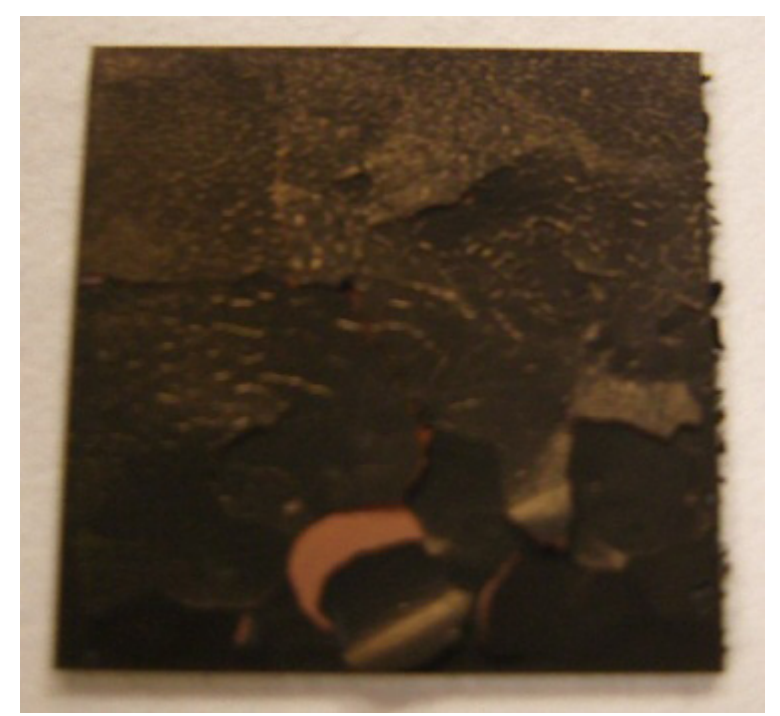

Fig. 4. Cracked film after thermal annealing.

$\mathrm{Al}$ was investigated using Joule heating. The heat released by the interfacial reactions was measured using DSC with an air flow rate of $20 \mathrm{ml} / \mathrm{min}$ and a heating rate of $10^{\circ} \mathrm{C} / \mathrm{min}$. DSC was carried out from 100 to $700{ }^{\circ} \mathrm{C}$. The final reaction compositions were identified by XRD after DSC analysis.

\section{RESULTS AND DISCUSSION}

In order to study the influence of annealing temperatures on the growth of $\mathrm{CuO}$ nanowires, the samples were annealed in a horizontal tube furnace at various temperatures for four hours. Figure 2 shows the $30^{\circ}$-tilted SEM images of the $\mathrm{Cu}$ films annealed in static air for four hours at $400^{\circ} \mathrm{C}, 500^{\circ} \mathrm{C}, 600^{\circ} \mathrm{C}$, and $700^{\circ} \mathrm{C}$. Uniform $\mathrm{CuO}$ nanowires only grew in the temperature range from 400 to $500^{\circ} \mathrm{C}$, as shown in Fig. 2(a) and (b). Only a few nanowires were formed when the temperature was $600^{\circ} \mathrm{C}$ or higher, as shown in Fig. 2(c). When the temperature was $700^{\circ} \mathrm{C}$ or higher, no nanowires were formed and the film surface was coated with small particles, as shown in Fig. 2(d). Based on the SEM images of the $\mathrm{CuO}$ nanowires, the optimum annealing temperature condition was determined to be $500^{\circ} \mathrm{C}$ for four hours, thus yielding uniform $\mathrm{CuO}$ nanowires. Figure 3 shows $30^{\circ}$-tilted 

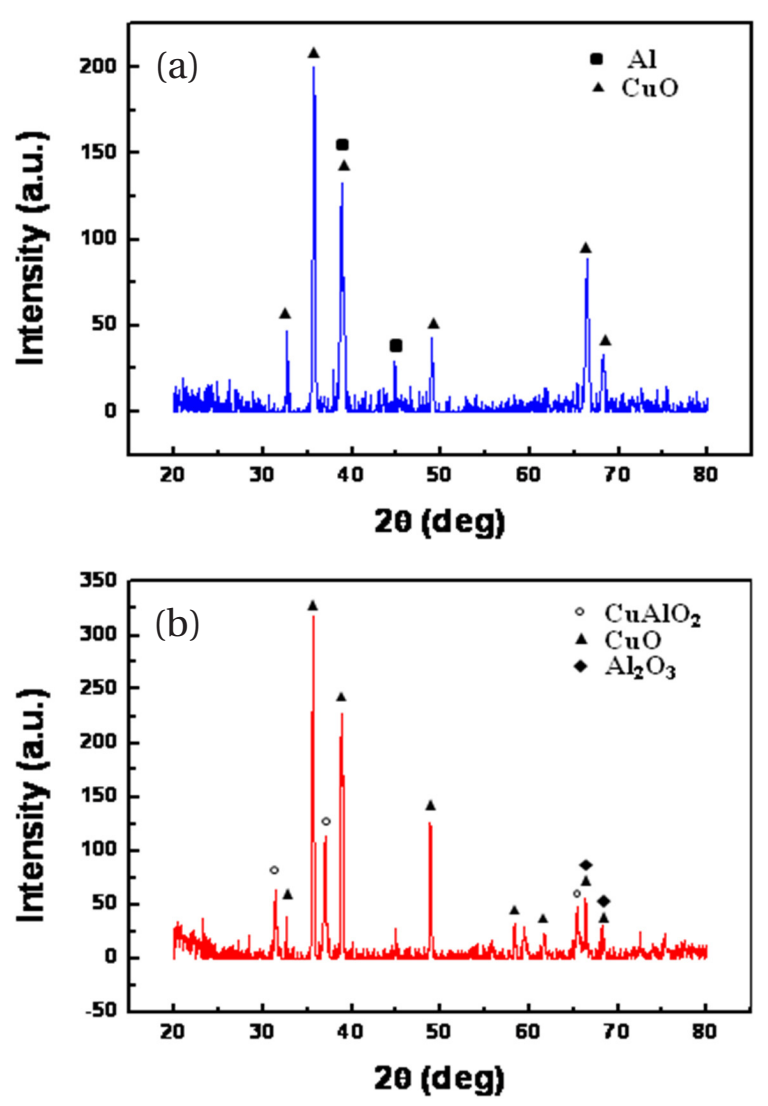

Fig. 5. XRD pattern of the $\mathrm{CuO}$ nanowires with deposited nano-Al (a) before the thermite reaction, and (b) after DSC analysis.

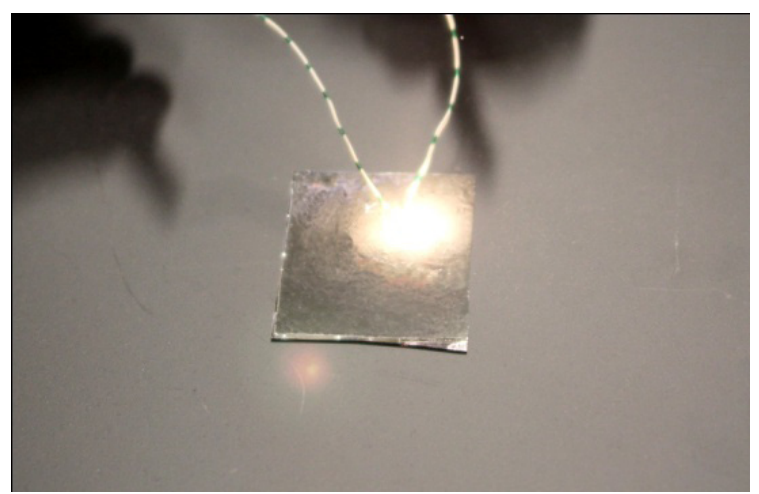

Fig. 6. Photograph of the explosive reaction of $\mathrm{CuO}$ nanowires coated with deposited nano-Al.

view SEM images of the CuO nanowires coated with uniformly deposited nano-Al.

As previously mentioned, high temperature annealing induced thermal stress might cause the film cracks shown in Fig. 4. To avoid film cracking, the film was allowed to naturally cool down in the furnace after thermal annealing. Figure 5 shows the XRD patterns of the $\mathrm{CuO}$ nanowires with deposited nano$\mathrm{Al}$. Only $\mathrm{CuO}$ and $\mathrm{Al}$ diffraction lines can be seen from the XRD patterns as shown in Fig. 5(a). There is no $\mathrm{Al}_{2} \mathrm{O}_{3}$ peak, indicating that no major reaction between $\mathrm{Al}$ and $\mathrm{CuO}$ nanowires occurred during the $\mathrm{Al}$ deposition, presumably due to the strong vacuum and low substrate temperature. Figure 5(b) shows the XRD pattern of the nanocomposite after DSC analysis. The final reaction products were identified as $\mathrm{CuAlO}_{2}, \mathrm{CuO}$, and $\mathrm{Al}_{2} \mathrm{O}_{3} ; \mathrm{CuAlO}_{2}$ is

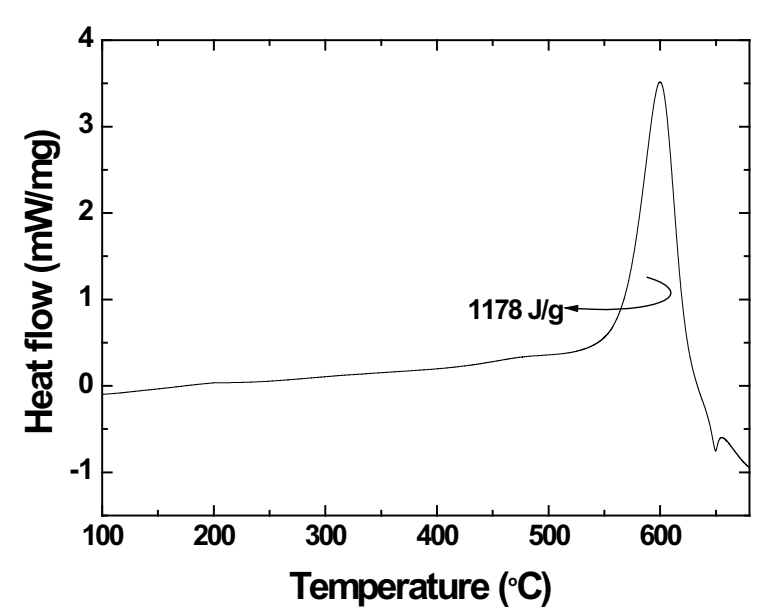

Fig. 7. DSC plots of $\mathrm{CuO}$ nanowires coated with deposited nano-Al.

formed from the reaction of $\mathrm{Al}_{2} \mathrm{O}_{3}$ and $\mathrm{CuO}$. The XRD pattern did not show the $\mathrm{Cu}$ and $\mathrm{Al}$ lines that should be present after reduction of $\mathrm{CuO}$ by Al. The photograph in Fig. 6 shows a bright flash of light produced by the explosive reaction between the $\mathrm{CuO}$ nanowires and the deposited nano-Al. The thermite reaction was ignited by Joule heating. The adiabatic frame temperature would potentially be above $2,000^{\circ} \mathrm{C}$ [8]. The thermite reaction between $\mathrm{CuO}$ nanowires and the deposited nano-Al can be written as

$$
3 \mathrm{CuO}+2 \mathrm{Al} \rightarrow 3 \mathrm{Cu}+\mathrm{Al}_{2} \mathrm{O}_{3}+\triangle \mathrm{H}
$$

where $\triangle H$ is the energy released during the reaction. To investigate the heat flows and onset temperatures of the exothermic reaction between the $\mathrm{CuO}$ nanowires and the deposited nano$\mathrm{Al}$, the nanoenergetic materials were characterized using DSC with a maximum temperature of $700^{\circ} \mathrm{C}$, as shown in Fig. 7. An exothermic reaction peak was produced by the thermite reaction between the $\mathrm{CuO}$ composite and the nano-Al. The DSC plots of the heat flow for the exothermic reaction shows the exothermic reaction peak of the $\mathrm{CuO}$ nanowires coated with deposited nano$\mathrm{Al}$. Integrating the area of the first exothermic reaction peak with DSC is the heat energy released by the exothermic reaction. The first exothermic reaction peak represents the nanocomposites prior to the aluminum melting peak at $660^{\circ} \mathrm{C}$. Nanoenergetic materials were achieved by the deposition of nano- $\mathrm{Al}$ on $\mathrm{CuO}$ nanowires, which resulted in good interface contact and reactivity. Impurities and $\mathrm{Al}$ oxidation were reduced by deposition in a strong vacuum and at a low substrate temperature. In this study, the heat energy from DSC was measured; it was approximately $1,178 \mathrm{~J} / \mathrm{g}$, which was higher than the $1,024 \mathrm{~J} / \mathrm{g}$ of a previous research study for selective area crystallization of a-Si [9]. $\mathrm{CuO}$ nanowires coated with deposited nano-Al can be used as a crystallization energy source of a-Si.

\section{CONCLUSIONS}

$\mathrm{CuO}$ nanowires on which nano-Al had been deposited were synthesized using a horizontal tube furnace and RF sputtering. $\mathrm{CuO}$ nanowires were grown from $\mathrm{Cu}$ film deposited onto a glass substrate after annealing. The best annealing conditions were found to be four hours at $500^{\circ} \mathrm{C}$. The length of the $\mathrm{CuO}$ nanowire was greater than $3 \mu \mathrm{m}$. To induce a thermite reaction, nano$\mathrm{Al}$ was deposited onto the $\mathrm{CuO}$ nanowires. A thermite reaction was induced by Joule heating. The heat energy was higher than the energy for a-Si crystallization. Finally, this thermite reaction 
could potentially be used for selective area crystallization of amorphous silicon films.

\section{ACKNOWLEDGMENTS}

This work was supported by the Korea Science and Engineering Foundation (KOSEF, R0A-2007-000-10044-0 [2007)) and by the Korea Research Foundation (KRF, KRF-2007-357-D00136 [2007)) of the Korean Government (MOST), as well as by LCD Business Samsung Electronics.

\section{REFERENCES}

[1] K. B. Plantier, M. L. Pantoya, and A. E. Gash, Combust. Flame 140, 299 (2005) [DOI: 10.1016/j.combustflame.2004.10.009].

[2] A. Prakash, A. V. McCormick, and M. R. Zachariah, Chem. Mater. 16, 1466 (2004) [DOI: 10.1021/cm034740t].
[3] J. Noro, A. S. Ramos, and M. T. Vieira, Intermetallics 16, 1061 (2008) [DOI: 10.1016/j.intermet.2008.06.002].

[4] J. Wang, E. Besnoin, A. Duckham, S. J. Spey, M. E. Reiss, O. M. Knio, and T. P. Weihs, J. Appl. Phys. 95, 248 (2004) [DOI: 10.1063/1.1629390].

[5] F. Mikulec, J. Kirtland, and M. Sailor, Adv. Mater. 14, 38 (2002) [DOI: 10.1002/1521-4095(20020104)14:1<38::aidadma38>3.0.co;2-z].

[6] M. Hossain, S. Subramanian, S. Bhattacharya, Y. Gao, S. Apperson, R. Shende, S. Guha, M. Arif, M. Bai, K. Gangopadhyay, and S. Gangopadhyay, J. Appl. Phys. 101, 054509 (2007) [DOI: 10.1063/1.2450672].

[7] X. Jiang, T. Herricks, and Y. Xia, Nano Lett. 2, 1333 (2002) [DOI: 10.1021/nl0257519].

[8] S. H. Fischer and M. C. Grubelich, 32nd AIAA/ASME/SAE/ASEE Joint Conference and Exhibit (Lake Buena Vista, FL 1996 Jul. 1-3) SAND95-2448C.

[9] J. H. Bae, D. K. Kim, T. H. Jeong, and H. J. Kim, Thin Solid Films 518, 6205 (2010) [DOI: 10.1016/j.tsf.2010.03.175]. 